\title{
An Examination of ICT Spending and the Development of E-Skills in the Republic of Turkey
}

\author{
Shahram Amiri, Joseph Woodside \\ Stetson University, DeLand, USA
}

\begin{abstract}
Turkey's information and communication technology (ICT) sector has made remarkable progress in the recent past according to various statistics. They have jumped 26 places on the network readiness index (NRI), from 71st place in 2010 to 45th place in 2013. Their gross domestic product (GDP) has doubled over the past decade. Their progress is the direct result of a variety of initiatives and public projects in concert with both foreign and domestic investment. Turkey has invested billions of dollars into their ICT sector in order to improve hardware, software, telecommunication, and IT infrastructure. This is all helping create a large demand for e-technology and e-skill in Turkey. This paper seeks to examine the effects of major spending initiatives (foreign vs. domestic investment) on GDP as well as the motives behind investment choices. There will be special emphasis regarding FATIH project-Turkey's highest dollar ICT project. The paper will include a comparison of GDP to a variety of data sets from the last five years, such as foreign direct investment, investment of public Turkish Lira, investment in hardware, etc. Furthermore, evidence found suggests that the largest public ICT project in Turkey-FATIH - which was a large scale investment in technology in schools — was likely more-economically motivated than educationally-motivated.
\end{abstract}

Keywords: information and communication technology (ICT), gross domestic product (GDP), network readiness index (NRI), the ICT development index (IDI), Turkey, socioeconomic development

\section{Introduction}

Turkey is strategically located at the intersection of Europe and the Middle East Africa. It is bordered by eight countries: Bulgaria, Greece, Georgia, Armenia, Iran, Iraq, Syria, and the Azerbaijani exclave of Nakhchivan. It is also bordered by the Aegean Sea to the west, the Mediterranean Sea to the south, and the Black Sea to the north. Turkey's location at the crossroads of Europe and Asia clearly makes it a country of geostrategic importance, when it comes to information and communication technology (ICT). Overall, Europe boasts higher rankings in ICT than countries in Asia or Africa. It should be noted that Turkey is not currently a member of the EU, but is in accession negotiations to become a member country. Turkey has the best network readiness index (NRI) ranking in comparison with all of its bordering countries. This shows that the methods Turkey is employing to improve their ICT are much more successful than the efforts of other neighbor counties in their region.

Shahram Amiri, chair of decision and information sciences, Stetson University, DeLand, FL, USA.

Joseph Woodside, assistant professor in decision and information sciences, Stetson University, DeLand, FL, USA.

Correspondence concerning this article should be addressed to Shahram Amiri, 421 N. Woodland Boulevard, Stetson University, DeLand, FL, 32723, USA. 


\section{Population}

Turkey has a growing population of 76 million. An interesting fact about Turkey's population is that it has one of the highest percentages of young people in the world (ages 15-24). Additionally, half of the population is under 30 (Turkish Statistical Institute, 2014). The ethnic groups which comprise the population are as follows: $70-75 \%$ Turkish, $18 \%$ Kurdish, and 7-12\% other minorities, according to a 2008 estimate (Central Intelligence Agency, 2014).

\section{Turkey's Education System}

Turkey's education system is predominantly public and centralized. Public schools are run by the Ministry of National Education (MONE). In 2012, Turkey's compulsory education system was extended from eight to 12 years, because access to upper secondary education is expected to increase, according to the Research Triangle Institute (RTI) and Education Reform Initiative (ERI) International report (RTI \& ERI International, 2013). Historically, Turkey has not been known to have the best quality of education in comparison to EU countries. Although they still have challenges ahead, it has been recognized that the overall quality of education in Turkey is improving. Investment in the educational system through ICT projects is a top priority for Turkey, as four of the top 10 biggest dollar public ICT projects were education-related.

\section{Economy}

There is no doubt that Turkey's economy is growing. According to the World Bank Group (2014), Turkey’s gross domestic product (GDP) has increased over 100\% from 2004 (\$392.2 billion) to 2013 (\$789.3 billion) and has the world's 15th largest GDP. Compared with EU countries, Turkey boasts the sixth largest economy. Its major exports include apparel, foodstuffs, textiles, metal manufactures, and transport equipment (Central Intelligence Agency, 2014). A large part of the economy is also tourism. Turkey is also a member of the G-20. Employment has been steadily increasing at a rate of 3\% annually.

According to the Turkish Statistical Institute (2014), the Turkish economy has received over $\$ 123$ billion of foreign direct investment over the past 10 years and as was rated as 13th most attractive FDI destination in the world.

\section{Research Analysis}

\section{Turkey's ICT Sector}

The current state of Turkey's ICT sector can be exposed by examining two indices: NRI and the ICT development index (IDI). The NRI is composed of a collection of sub-indexes which evaluate the impact of information and communication between the years 2004-2012 (Deloitte, 2014).

The IDI examines ICT at the global level and benchmarks the ICT readiness and usage of various economies. The IDI ranks countries' performance with regard to ICT infrastructure and uptake.

\section{Turkey and the IDI}

The overall trend of Turkey's ranking on the IDI index seems to indicate that they are in fact falling behind with regards to ICT infrastructure and uptake when compared to other countries. If you cross-reference this with the NRI ratings (shown in Figure 1), it becomes clear that uptake (usage) seems to be Turkey's weak point.

\section{Turkey and the NRI}

Figure 1 illustrates the rankings, over time, of the four sub-indexes which make up the NRI. It is easy to see from this chart that Turkey continues to improve in every sub-index year after year, with the exception of 
the "usage sub-index". The scores from the four sub-indexes aid in determining the overall NRI ranking. According to 2013's NRI, the republic of Turkey ascends seven places to an overall rank of 45 from a rank of 52 in 2012.

Turkey has made significant improvements in its political and regulatory framework, business/innovation environment, and has improved in developing ICT infrastructure. Some of Turkey's weaknesses include being a late-comer in regards to launching mobile broadband services in 2009 (International Telecommunication Union, 2013).

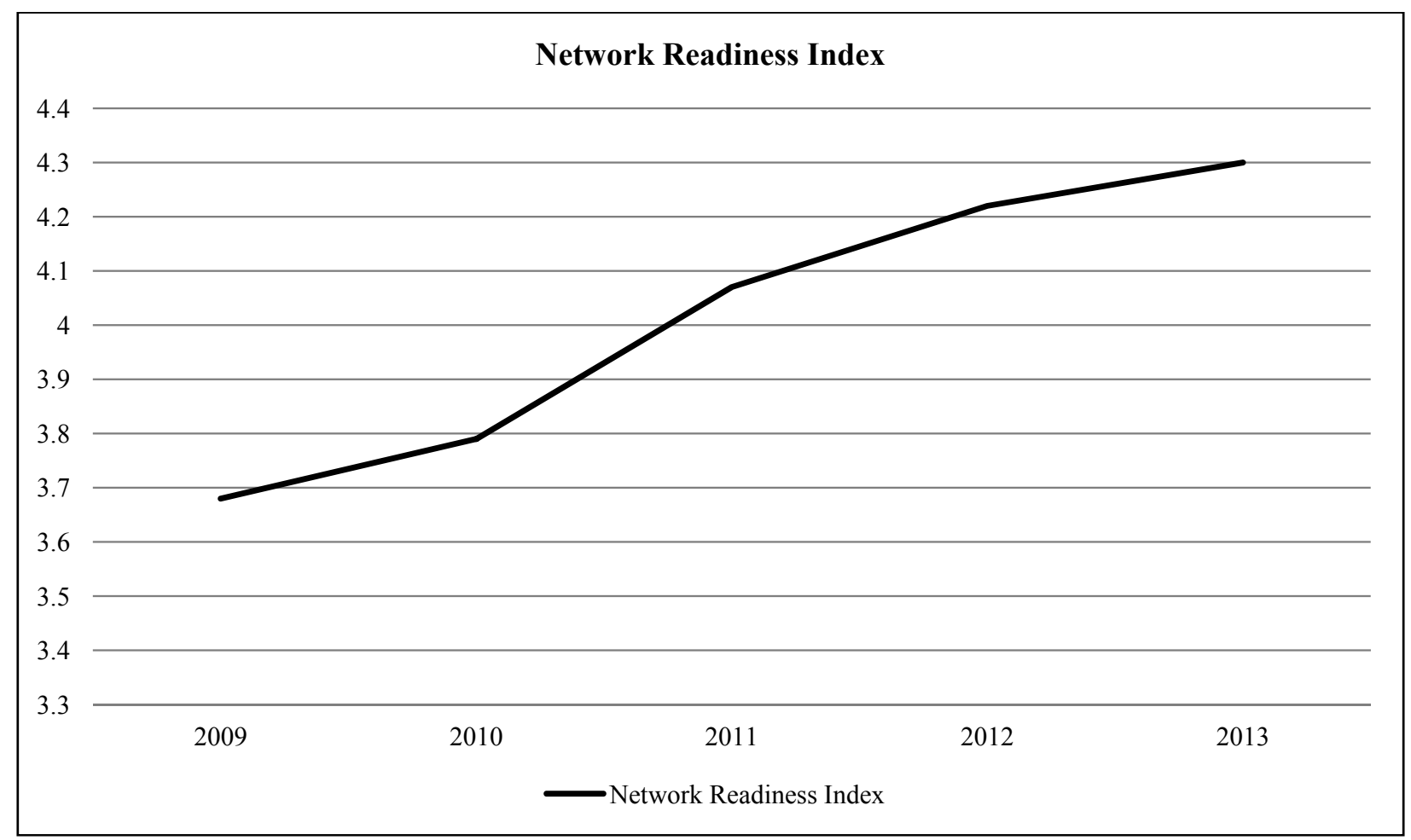

Figure 1. Gaph of the network readiness index over time, for Turkey.

\section{NRI and GDP}

When cross-referencing sub-indexes of the NRI data with GDP, a picture of how Turkey is accomplishing results in the ICT sector starts to emerge. The correlation between GDP and the overall NRI ranking is $r=$ 0.107. This number tells that as GDP increases, the NRI index for Turkey should improve. Conversely, this number tells that as ICT improves, so does GDP. This correlation is relatively weak, but there is a small sample size. This means that the data are easily affected by outliers.

The improved ranking of the business innovation and environment sub-index was likely due to the continued development of "technology development zones" as well as other concessions and laws Turkey has enacted to encourage businesses to develop ICT technologies within its borders. The improvement in the infrastructure and digital content sub-index was likely due to the large investments made by Turkish companies in infrastructure, such as Vodafone \& Turkcell.

\section{Turkey's ICT Future and Goals}

According to a report from the Investment Support and Promotion Agency (2014), Turkey is actively seeking investment to become one of the top 10 countries in e-transformation. To do this, the government set a 
number of ambitious goals for the ICT sector to be reached by 2023. The main goal is to reach an ICT sector size of $\$ 160$ million, a market growth of around 15\% annually, and a sector share of $8 \%$ GDP, up from $2.9 \%$.

Other stated that goals of the Republic of Turkey include:

- reaching 30 million broadband subscribers;

- providing internet connection for 14 million houses at a speed of 1,000 Mbps;

- having $80 \%$ of the population computer literate;

- increasing the number of companies to 5,500; employees to 65,000; and exports in USD to 10 billion in TDZs (Technology Development Zones);

- Increasing the research and development expenditure to GDP ratio to $3 \%$ from $0.85 \%$.

\section{Initiatives to Advance E-Technology and E-Skill}

The specific benchmarks listed in the previous section indicate that the Turkish government is very in tune with the current state of their ICT sector and has very precise goals for the future of ICT in Turkey. The following will describe various initiatives underway which Turkey hopes will turn their above-stated goals into realities.

\section{ICT Support Organizations}

There are four major government-supported organizations whose purpose is to support the ICT sector; the Ministry of Science, Industry, and Technology, the Ministry of Transport, Maritime Affairs and Communication, the Scientific Research and Technological Research Council (TUBITAK), and the Information and Communication Technologies Authority (ICTA).

The Ministry of Science, Industry, and Technology was founded in 2011 and its main purpose is to "promote scientific thinking and create a knowledge-based society" (Deloitte, 2014). The Ministry of Transport, Maritime Affairs, and Communication has been around since 1939, much longer than the Ministry of Science. Their projects tend to be a little broader in scope. One of their most recent initiatives was the establishment of the Internet improvement board. Their goal is to improve the use and safety of the Internet in Turkey. TUBITAK was established in 1960. According to their website, TUBITAK represents Turkey on international research activities and organizes publications, scholarships, and grants for work done in the scientific/technological fields. The ICTA is a regulatory agency established in January 2000. They create delegations, are a service provider of electronic certificates, and they also provide IT risk management services.

\section{Technology Development Zones}

Technology development zones (TDZs), briefly mentioned above as part of Turkey's ICT goals, were put on Turkey's agenda by the Prime Ministry State Planning Organization in 1989 (The Coordination Council for the Improvement of Investment Environment, 2009). Technology Development according to the Zones Law No. 4691 is defined as: "Sites integrating academic, economic, and social structures at or near the campus of certain universities; advanced technology institutes; an R\&D centers or institutes; or a Technopark involved in these same areas of work. They are sites where companies using advanced technology or companies with a new technological orientation, produce and develop technology or software by through the facilities provided by the organizations mentioned above. They are involved in activities which transform a technological innovation into a commercial product, method or service and by this means contribute to the development of the region".

The objectives of TDZs include: produce technological know-how, develop innovations in products and production methods, enhance product quality or standards, commercialize technological know-how, support technology-intensive production and entrepreneurship, ensure the adaptation of small and medium scale 
enterprises to new and advanced technologies, create employment for people with research qualifications, and provide the technological infrastructure for the acceleration of the inflow of foreign capital which will bring advanced technology into Turkey (The Coordination Council for the Improvement of Investment Environment, 2009).

Companies within technology development zones are granted various supports and exemptions totaling 1.4 billion Turkish Lira (Deloitte, 2014). Since the 1990's, 36 TDZs have been built and 14 more are under construction for a total of 2,209 companies. Turkey currently has 129 ICT related research and development centers and is still building more.

\section{Law No. 5746}

Similar to TDZs, law No. 5746 supports and encourages development of technology by encouraging the establishment of research and development centers which will assist the Turkish economy in becoming globally competitive through research and development and innovation via exemptions and government support. This law supports research and development centers for various industries, 13 of the total 142 are dedicated specifically to ICT.

\section{Seeking Foreign Investment}

Turkey is actively seeking foreign investment to support its growing ICT sector in order to reach its 2023 goals (Investment Support and Promotion Agency, 2014). There are a number of agencies, online brochures, websites, reports, etc. which aim to attract foreign investment for the promotion of ICT and e-technology in Turkey.

\section{E-Devlet Project}

The E-Devlet project is a project conducted by the Ministry of Transport, Maritime Affairs, and Communication. The goal of the project is to gather all state utilities and make them accessible on one site and to increase access to public services using ICT. Transitioning to the new electronic ID system is part of this project.

\section{Fatih Project}

The Fatih project (Today's Zaman, 2012) is a government initiative which stands for "the movement to increase opportunities and technology". The project aims to integrate state-of-the-art technology into Turkey's public education system. The project was launched in 2012. Initiatives of the project include distributing e-tablets to every student enrolled in grades 5-12, installing smart boards in every classroom, and launching an e-learning or distance learning component. Fatih is expected to cost three billion Turkish Lira. The project, which was initially launched in secondary schools but will eventually reach all grade levels between 2011 and 2019, has five main components as laid out in the official Fatih website (Milli Eğitim Bakanlığı, 2012):

- providing equipment and software substructure;

- providing educational e-content and management of e-content;

- effective usage of the ICT in teaching programs;

- in-service training of the teachers;

- conscious, reliable, manageable, and measurable ICT usage.

\section{ICT Spending Analysis}

With varying agendas for foreign and domestic funds, investigating the effects of these investments on GDP is the core investigation of this paper. After analyzing Figure 2, it is easy to see the visual relationship 
between foreign direct investment (FDI) spent on the ICT sector and GDP. If Turkey is successful at increasing their FDI for the ICT sector, the potential effect it could have on GDP could be enormous. This is especially true when you consider that in 2012; only $1.02 \%$ of FDI was spent on the ICT sector (which amounts to $\$ 133$ million USD).

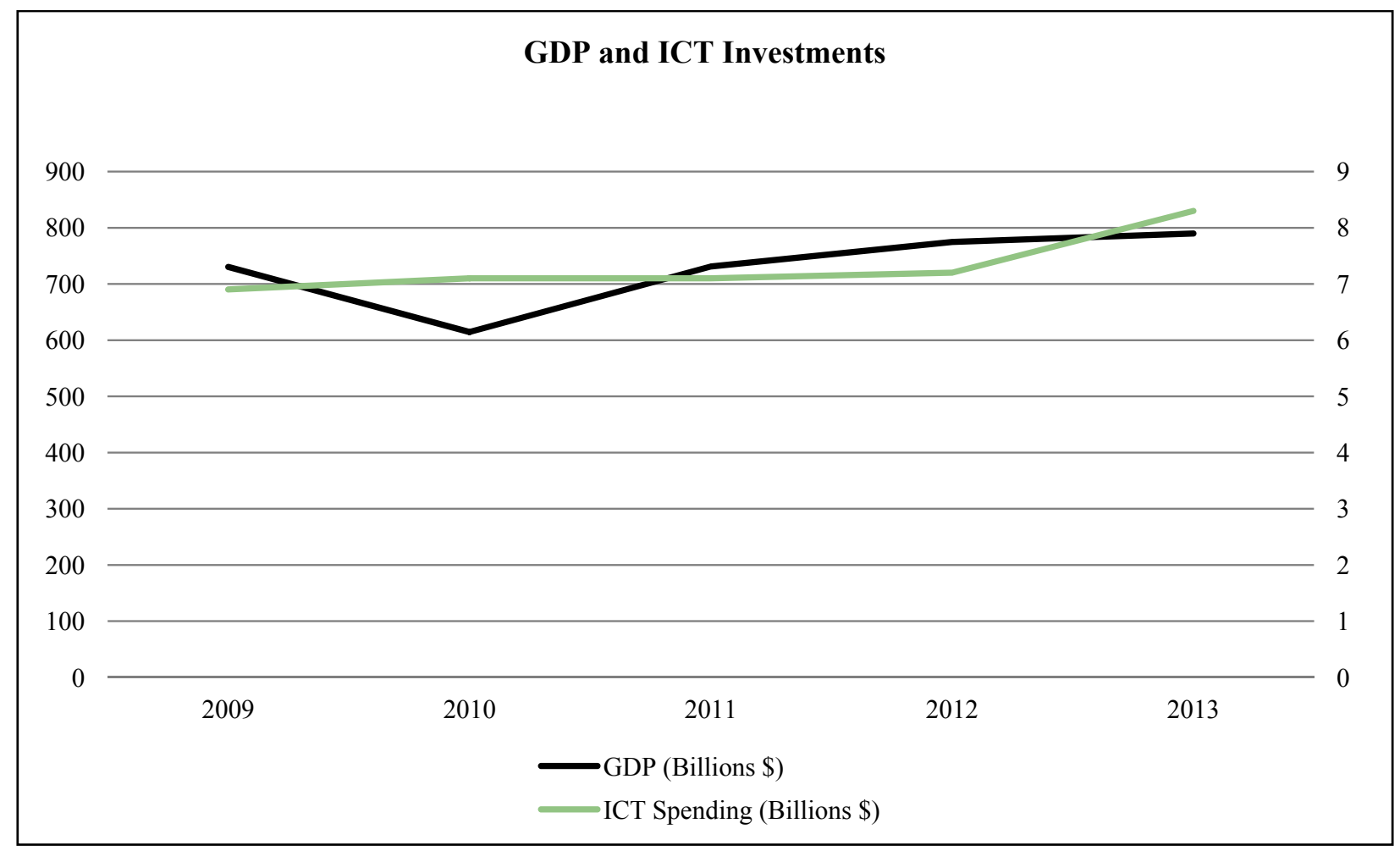

Figure 2. Line graph comparing FDI, GDP, and ICT investments in Turkey from 2009 to 2012.

According to the 2013 ICT industry report, from 2010 through 2012, substantially more FDI inflows were used on the manufacture of computers, electronic-electrical, and optical equipment and less on information and communication services. This indicates that directing funds towards the manufacture of hardware and equipment could have a relationship with GDP.

It is also quite clear from Figure 2 above that the public fund Turkey is investing in the ICT sector clearly outpaces GDP growth. This seems to be an indication that the Turkish Lira (TL) invests are not as efficiently invested as the FDI monies are, at least at this time. This leads to the logical question-what is Turkey spending its public funds on.

The ICT Turkey industry report describes the top 10 public ICT projects in 2012, in millions of TL. In 2012, the Fatih project leads ICT related investments in all of Turkey's public sector investments, costing 803 million TL and using up 32.4\% of ICT sector investment in 2012. The data indicate that the public spending on the ICT sector did not have strong correlation with GDP between 2009 and 2012. This is confirmed by the following quote from the ERG and RTI 2013 report,

There is little evidence to be found internationally about the actual economic impact of other large-scale technology initiatives like Fatih, but a report from the Turkish Ministry of Development suggests that the impact of total investment in Fatih will not have a long-term (2023) impact on GDP growth. (ERG \& RTI International, 2013, p. 8) 
Although short-term effects on GDP would not be expected by this type of initiative (Fatih), since it is an investment in Turkey's future generations, it is interesting to note that experts in the field do not believe that it will necessarily have a long-term effect on GDP either. It is clear to see that public spending is not currently having a profound effect on GDP, so why is Turkey allocating so much of their public funds to Fatih? This will be investigated further in the following section (ERG \& RTI International, 2013).

\section{Fatih's Plan: A Means to What End}

The Fatih project has been called "one of the world's largest technology projects of its kind". It is clear from the data to the right that Turkey has made it a top priority, when it comes to allocating ICT spending. This finding prompted further investigation into how the project is being conducted.

According to the ERG \& RTI International report,

....at least 63 thousand tablets were distributed to students and 84 thousand classrooms were equipped with interactive whiteboards (IWB) as part of initial distributions; the tablet procurement process is underway, and the authors expect considerable program deployment in the 2013-2014 school year for thousands of classrooms across the country. (ERG \& RTI International, 2013, pp. 3-4)

This brings to the question: Why did Turkey choose the distribution of whiteboards and tablets as its main focus of the Fatih project. According to the ERG \& RTI 2013 report, economic transformation could be a key driver. Turkish manufacturers contributed significantly to the production of technologies deployed under Fatih. Turkish companies manufactured the whiteboards as well as hardware components of the tablets. Perhaps the government was looking more for short-term stimulus to the economy than long-term effect on GDP with the Fatih project. Spending the money under the veil of educational improvement was probably an easier way to sell this form of stimulus spending to the public. While the implementation goals of Fatih are very clear, such as how many tablets and whiteboards they want distributed to " $x$ " amount of students, the ultimate results they expect are not. While the ERG \& IRT were creating their 2013 report, one official from MONE told ERG \& IRT that some of their expected outcomes include the following: more engaged learners, increased and improved collaboration between students, reduced text book costs, increased use of visual, auditory and kinesthetic learning methods including games and simulations, and more robust use of analytics. What is interesting about this statement is that almost none of these expected outcomes are measurable with the exception of reduced text book costs. This evidence shows that the Fatih project is most likely more economically motivated than educationally motivated (Hakan \& Faruk, 2013).

While combing through the 100 page 2013 ICT industry report for Turkey, the true purpose of the Fatih project is revealed: The Fatih project in education is a mega-project that will support the hardware sector. Out of all the literature encountered, this statement was the only indication that there was an agenda other than promoting the use of technology in the classroom, it seems that Fatih is not as much about the children as most of the government literature on the project leads one to believe.

Testing the relationship between spending on hardware (current demand) and GPD seemed to be the next logical step to see whether this spending to promote the hardware part of the ICT sector is justified based on past results. The correlation between IT spending on hardware (demand from Turkish citizens) and GDP between 2007 and 2012 was not as strong as expected, $r=-0.012$ suggests that IT spending on hardware has not had significant impact on GDP when examining historical data. This does not mean that Turkey is not 
heading in the right direction. Analysis from TUBISAD, the Turkish Informatics Industry Association, proposes that the hardware sub-sector constitutes more than two thirds of the IT market, excluding the communications sector. Liquid crystal displays and other audio-visual devices, telecom components, mobile phones, and other communication equipment are expected to be the major sources of technology spending in Turkey, according to the 2013 ICT industry report (International Telecommunication Union, 2013).

\section{Conclusions}

Although historical evidence indicates that foreign monies were more efficiently spent than public (domestic) funds, this analysis found that most invested monies were actually being allocated for similar purposes. It seems that spending on hardware is expected to increase a faster pace than the actual historical data show. This suggests that the Fatih project could be part of the government's plan to help ramp up the hardware sub-sector in preparation for increased demand to come in the years 2013 through 2017. This is further supported by the relationship between FDI and GDP in the past, as the FDI funds at the period of analysis were used significantly more on the manufacture of hardware and equipment as opposed to being spent on communication services. It turns out that despite the fact that public projects appeared to be centered on other initiatives - all projects lead back toward the hardware sector.

Opponents to the Fatih project who may think it is not an efficient allocation of public funds may want to consider that Fatih promotes and supports the hardware subsector of the economy, which is the biggest contributor to the ICT sector in Turkey. It will help grow and sustain demand for e-technology and e-skill, once the sizeable younger generations begin to enter the marketplace. It may also have the other desired positive effects on other sectors, education for example, by increasing the engagement level of students and increasing performance against other nation's students. The positive effect on education in Turkey could be profound, if educators took the time to ensure that the technologies were being utilized to its fullest extent. The Turkish government should continue on its path toward making Turkey an accessible place to conduct business, as Turkey's location lends itself to be a strategic geographical and technological hub. This combined with continuing to involve domestic companies in contributing to laying the foundation of infrastructure needed to support the future demand is paramount. Thus far, Turkey has made remarkable progress in the development of e-skill and e-technology. Turkey should continue to see the relative improvement of their IDI and NRI rankings given the initiatives they have taken to improve the usage and uptake of new technology.

\section{References}

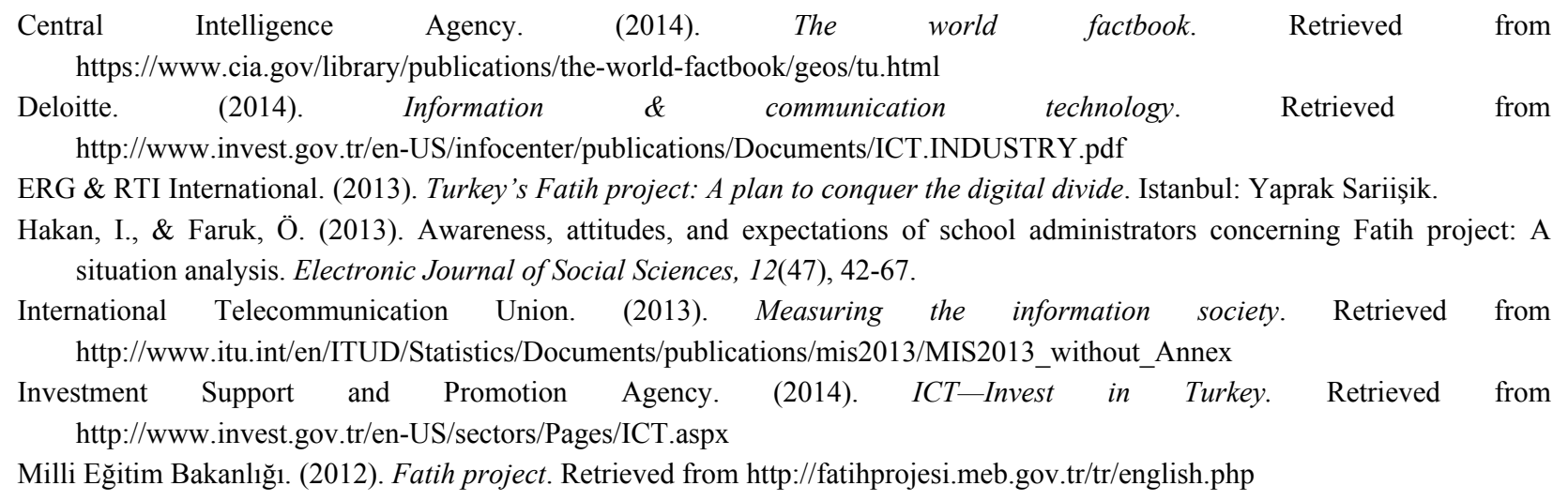


The Coordination Council for the Improvement of Investment Environment. (2009). Technology development zones. Retrieved from http://www.yoikk.gov.tr/dosya/up/eng/TDZ.pdf

Today's Zaman. (2012). Turkey launched ambitious Fatih project in public education. Retrieved from $\mathrm{http} / /$ www.todayszaman.com/news-270656-turkey-launches-ambitious-fatih-project-in-public-education.html

Turkish Statistical Institute. (2014). Population statistics. Retrieved from website: http://www.turkstat.gov.tr/Start.do

World Bank Group. (2014). International economics. Retrieved from http://www.tradingeconomics.com/turkey/gdp 